\title{
Construção social da demanda em saúde
}

| 1 Carolina Rogel Souza, 2 Carlos Botazzo |

Resumo: A atenção à saúde no Brasil se dá por meio de um sistema de saúde único, com base jurídica e apoio na Constituição Federal. A saúde é colocada como direito de todo cidadão, e para tanto são definidos modelos com vistas à operacionalização dos serviços organizados para esse fim. O primeiro nível no Brasil é denominado Atenção Básica (AB), com sua base conceitual vinda da Atenção Primária à Saúde (APS). O objetivo deste trabalho é conhecer e analisar como está organizada a produção teórica da Saúde Coletiva no Brasil acerca da construção social da demanda por serviços de saúde na Atenção Básica, com o intuito de criar uma referência para se pensar a mesma. A pesquisa foi feita utilizando-se os termos relacionados ao problema inicial: demanda em saúde, atenção básica e modelos tecnoassistenciais em saúde.

> Palavras-chave: Atenção Primária à Saúde; cuidado em saúde; demanda em saúde; necessidades de saúde.

\author{
1 Fonoaudióloga; mestre \\ em Ciências Odontológicas, \\ Universidade de São Paulo; \\ especialista em Saúde Coletiva \\ (IS/PAP/FUNDAP) Endereço \\ eletrônico: carolrogel@yahoo. \\ com.br \\ ${ }^{2}$ Cirurgião dentista; livre- \\ docente pela Universidade de \\ São Paulo; doutor em Saúde \\ Coletiva (FCM/UNICAMP). \\ Endereço eletrônico: \\ cbotazzo@hotmail.com
}

Recebido em: 29/11/2012 Aprovado em: 14/06/2013 


\section{Introdução}

As discussões sobre a estruturação do Sistema Único de Saúde (SUS), parcialmente finalizadas com a promulgação da Constituição Federal em 1988 e com a Lei no 8.080/1990, tiveram início no final da década de 1970 em um momento de emergência da participação da sociedade na definição e implementação de políticas sociais e direitos de cidadania. Àquela altura, em plena ditadura militar, a sociedade civil encontrou novas formas de se manifestar em resposta ao aumento das desigualdades ocorridas por conta da política econômica e do recrudescimento da repressão política adotada pelo regime. Mesmo sob ameaças, os grupos sociais emergentes, entre os quais trabalhadores industriais urbanos e estudantes, passaram a reivindicar melhorias na educação, moradia, transporte e saúde e, mais além, do direito de expressão e de organização livre.

É importante que se resgate, ainda que em breves palavras, um pouco do percurso histórico que resultou na criação de um sistema de saúde universal no Brasil. De fato, a história da saúde pública brasileira experimentou avanços lentos, e muitas vezes rupturas ou descontinuidades que devem ser consideradas. $\mathrm{O}$ abandono a que estavam relegadas as populações do interior do país, e mesmo nas grandes cidades, pode ser constatado pelas péssimas condiçōes de saúde, com incidência, mesmo no começo do século XX, de epidemias e surtos de doenças transmissíveis. A República, herdeira do Império, não tinha como propósito ser república para todos, antes representando um pacto conservador das elites agroexportadoras. Só muito mais tarde, ainda no século XX, esse equacionamento pode encontrar solução e ser dado início ao resgate da enorme dívida social que se acumulara. Lento que fosse, com as greves de 1915 e de 1917, além da pandemia de gripe espanhola de 1918, chegou-se à conclusão de que era necessária uma reforma dos serviços de saúde, a fim de assistir a população e, sobretudo, segmentos dos trabalhadores urbanos (ESCOREL; TEIXEIRA, 2008).

É assim que o processo político-organizativo de um sistema de proteção social foi se conduzindo por entre crises e rupturas, num longo percurso iniciado em 1923, com a instituição das Caixas de Aposentadorias e Pensões (CAPs), criadas pela Lei Eloy Chaves, até a tentativa de ordenamento jurídico do sistema previdenciário e de seguridade, representado pela Lei Orgânica da Previdência Social (LOPS) de 1962, já no governo João Goulart (SANTOS, 1979). 
Antes disso, o governo Vargas expressava por meio da oferta de serviços de saúde aos trabalhadores um dos pontos de ancoragem da integração nacional e de suporte político ao seu mandato. Tal oferta se materializava em duas vertentes, claramente distintas: de um lado, a saúde pública, e de outro, serviços de assistência médica previdenciária. A primeira dizia respeito às açōes de saúde voltadas ao combate às endemias e epidemias, com caráter coletivo. Já a segunda tratava da assistência aos trabalhadores de certos ramos da produção que contribuíam para o sistema previdenciário (ESCOREL; TEIXEIRA, 2008).

Este modelo bifronte aumentou seu grau de fragmentação, agravado a partir do Regime Militar, mesmo com as tentativas de unificação, observando-se clara hegemonia da previdência social sobre a saúde pública, agora conduzida pelo Instituto Nacional de Previdência Social (INPS) e seu parente próximo, o Instituto Nacional da Assistência Médica da Previdência Social (INAMPS), criado em 1975. Todas essas estruturas posteriormente acabaram integrando o Sistema Nacional de Previdência e Assistência Social - SINPAS (ESCOREL; TEIXEIRA, 2008).

Para as mesmas autoras, com o INPS a "[...] previdência passou a ter função assistencial e redistributiva, ainda que esta estivesse limitada ao contingente de trabalhadores com carteira assinada" (ESCOREL; TEIXEIRA, 2008, p.389). Quem não contribuía para a previdência recebia cuidados de saúde nos centros de saúde pública, quando enquadrados em algum dos programas, caso contrário tinham que recorrer à filantropia ou ao mercado privado. Aos poucos, o INAMPS introduziu a contratação de serviços de terceiros, com a alegação de incapacidade da rede própria de suprir a demanda por atendimento, e essa terceirização foi um dos fatores agravantes da crise instalada em meado dos anos de 1980.

É nesse contexto que o movimento da Reforma Sanitária passou a questionar o modo de fazer saúde no país, propondo um novo arranjo diferente do preconizado até então, de caráter individualista, médico-centrado e hospitalocêntrico, de acesso restrito a parcelas da população. Tal movimentação em torno do tema culminou com a proposição de princípios e diretrizes para a saúde, discutidos e referendados na $8^{\text {a }}$ Conferência Nacional de Saúde (CNS), realizada em 1986. Os princípios defendidos na resolução final da Conferência foram depois consagrados na Constituição de 1988, sob o lema "Saúde: Direito de Todos e Dever do Estado" (STOTZ, 2004). O SUS que nascia, além de propor uma nova forma de estruturação do sistema, colocava-se em contraponto à perspectiva 
neoliberal, claramente apresentada no Capítulo da Seguridade Social da nova Constituição, cujo artigo 196 enfatiza:

A saúde é direito de todos e dever do Estado, garantido mediante políticas públicas sociais e econômicas que visem à redução do risco de doença e de outros agravos e ao acesso universal e igualitário às ações e serviços para sua promoção, proteção e recuperação (Brasil, 1988).

As formas de regulamentar o novo sistema e operacionalizar suas ações são explicitadas com um elenco de princípios: universalidade, integralidade e equidade; e suas correspondentes diretrizes: descentralização, regionalização, hierarquização e participação social.

A universalidade diz respeito ao acesso dos usuários aos serviços e açôes de saúde; a integralidade faz referência às opções terapêuticas disponibilizadas para que o paciente tenha assegurada a manutenção ou a reabilitação de sua saúde; a equidade, finalmente, trata da maneira como o sistema dá conta das diferenças implicadas na manutenção da saúde, sejam elas das mais variadas ordens, sociais ou econômicas.

As diretrizes versam sobre formas de operacionalização do sistema: a descentralização da gestão dos serviços indica quais os atores que serão responsáveis por quais serviços da rede, e isto se dá com a transferência da gestão de certas unidades para os municípios e estados; a regionalização coloca a necessidade de delimitação dos territórios a serem cuidados por cada serviço; a hierarquização vem colocada na forma da organização de níveis de serviços, de acordo com suas complexidades de cuidado; a participação social insere a sociedade no planejamento e proposição da política e ações de saúde nos territórios. Tais princípios e diretrizes são coalescentes com uma rede hierarquizada de serviços, classicamente denominadas de atenção primária, secundária e terciária, não na tradicional forma de pirâmide, mas em rede, propriamente, com níveis diferenciados de complexidade das ações e tecnologia agregada.

O primeiro nível, no Brasil, é denominado Atenção Básica (AB), com sua trama conceitual oriunda da Atenção Primária à Saúde (APS). É reiterada como a porta de entrada preferencial do sistema, ordenadora e coordenadora do cuidado, com um território delimitado e exercida nas Unidades Básicas de Saúde (UBS) e/ ou Unidades de Saúde da Família (USF). Seguindo a diretriz da descentralização, é gerida pelo município, e com isso espera-se que as açōes sejam mais qualificadas e resolutivas, uma vez que o município supostamente tem maior proximidade e 
conhecimento das necessidades de saúde de sua população.

Espera-se que a Atenção Básica seja capaz de desenvolver ações de vínculo e responsabilização entre as equipes de saúde e a população residente em seu território adscrito, garantindo a continuidade e o cuidado longitudinal aos usuários (BRASIL, 2007). Espera-se, também, por ser o primeiro contato do indivíduo com o sistema de saúde, que seja capaz de resolver uma gama de necessidades de saúde que extrapolam a esfera da intervenção curativa individual (SCHRAIBER; MENDES-GONÇALVES, 1996).

Um dos modos propostos para acolher as demandas em saúde é a organização de programas. Os programas de saúde, planejados pelas diferentes esferas de governo, levam em conta a dimensão epidemiológica do adoecimento, organizando os serviços na lógica da doença ou dos grupos com maior risco de contraí-la. Assim, ao integrar um desses programas, o paciente passa a assumir a identidade da doença que possui, sendo informado dos procedimentos que deve seguir, dentro do serviço e em sua vida cotidiana (PINHEIRO; CAMARGO JR, 2000).

$\mathrm{Na}$ formulação desses programas, desconsidera-se a participação de outros atores que também estão implicados no processo e, fundamentalmente, o próprio sujeitopaciente. Prima-se pelo rigor técnico das ações, deixando-se de lado as questões subjetivas do sujeito diretamente implicado. Isso ocorre porque o que é pensado como sendo o ideal pelos técnicos nem sempre corresponde à situação real da população, pois não são considerados aspectos sociais, econômicos, culturais etc.

As unidades de saúde valem-se dos conceitos da epidemiologia e da vigilância em saúde para organizar um leque de serviços que serão ofertados à população adscrita em seu território, visando oferecer respostas aos principais problemas de saúde segundo certa racionalidade. Esta resposta vem, geralmente, na forma de uma consulta - médica, de enfermagem ou odontológica - fazendo com que a necessidade de saúde do sujeito seja associada ao consumo de um serviço consultas e procedimentos (SCHRAIBER; MENDES-GONÇALVES, 1996).

Esse descompasso conduz muitas vezes a uma dupla insatisfação, pois o serviço oferece a consulta somente como resposta às demandas do usuário e este, por sua vez, somente busca por ela, fazendo com que outras propostas de cuidado sejam secundarizadas e até mesmo abolidas. Assim, seria preciso apostar em mudanças no processo de trabalho instaurado no nível primário, promovendo a um só tempo uma mudança no olhar e nos modos de fazer, 
com consequente mudança de foco para as necessidades de saúde, ao invés de privilegiar os problemas ou doenças (NERY, 2006).

Para Stotz (1991, apud SILVA et al., 2003, p.237), “[...] problemas e necessidades de saúde apresentam-se como noçōes conexas: a necessidade é, de algum modo, a tradução de problema em termos operacionais." As necessidades de saúde estão no nível das necessidades sociais mais gerais. São construídas social e historicamente e espelham as mediações da prática social dos sujeitos, individuais e coletivas que, em interação com o centro da sociedade civil, lutam pela saúde.

Em sua dissertação, Matsumoto (1999, p. 115) trabalha com a ideia de que as necessidades de saúde poderiam ser apreendidas e organizadas em quatro grandes conjuntos:

1. "ter boas condições de vida";

2. "ter acesso e poder consumir toda tecnologia de saúde capaz de melhorar e prolongar a vida";

3. “[...] criar vínculos (a)efetivos entre cada usuário e uma equipe e/ou um profissional [...]";

4. “[...] ter graus crescentes de autonomia no seu modo de levar a vida”.

O modelo de saúde adotado busca objetivar a demanda traduzida como doença, tornando-a real. O que levaria o usuário ao serviço é a necessidade de curar ou evitar um agravo. Assim, passa-se a propor modelos de atenção à saúde que organizem os serviços no sentido de acolher essa doença ou o agravo estabelecido, ou a evitar que ele se instale.

O cuidado em saúde é predominantemente pensado e organizado a partir desta lógica, dentro das unidades de saúde, mas estas não conseguem trabalhar, sozinhas, todas as questóes que influenciam e determinam a saúde e a doença das populações. Questões de ordem econômica e social, inclusive de infraestrutura e habitabilidade, e as ligadas extensamente aos "modos de levar a vida" modos possíveis, diga-se -, necessitam da ação de outros atores para que sejam solucionados ou minimizados. Para tanto, serviços e instituições devem alinhar informações no sentido de tornarem claras, umas às outras, a forma como se dão em seu interior os processos de trabalho, o que estão preparados a atender e, a um só tempo, propor ações conjuntas com vistas às necessidades levantadas. 
Tendo em conta este recorte, neste artigo buscamos analisar criticamente as

principais contribuições teóricas que concernem aos temas em debate sobre a construção social da demanda em saúde.

\section{Percurso teórico}

\section{Modelos de atenção em saúde}

Modelos assistenciais são formas de se pensar e organizar os serviços de saúde, no sentido de garantir a efetivação da assistência e do cuidado a todos que necessitam. Envolvem os aspectos técnicos do cuidado, a estrutura física dos serviços, as ações que serão realizadas e de que forma tudo isso será ofertado ao indivíduo que busca pelo sistema de saúde.

No Brasil, a discussão acerca dos modos de se organizar o sistema de saúde tem por referência os debates internacionais em torno do tema, e como pano de fundo, a própria construção crítica do SUS no cotidiano dos serviços, no âmbito da gestão e da produção teórica. Paim (2008, p.554) coloca que o modelo de atenção "[...] pode ser definido como combinaçôes tecnológicas estruturadas para a resolução de problemas e para o atendimento de necessidades de saúde, individuais e coletivas". Ou seja, são combinaçôes de técnicas e conhecimentos visando à satisfação das mais variadas necessidades de saúde expressas pela população. São representações da realidade de saúde de um dado território, conhecidas por meio da articulação dos saberes técnicos e locais, da comunidade, indo além da mera proposição de fluxos e serviços a ser ofertados.

Teixeira e Solla (2006, apud PAIM, 1993, p.24) apresentam duas formas de se organizar o sistema de saúde: o "modelo assistencial" e o "modelo de atenção em uma perspectiva sistêmica". O primeiro utiliza a teoria do processo de trabalho em saúde como referencial e o segundo, a perspectiva de um sistema de saúde organizado de forma sistêmica.

O modelo assistencial visa à resolução de problemas de saúde e à satisfação das necessidades, utilizando-se da combinação de saberes e práticas. Por isso, são consideradas:

[...] formas de organização das relações entre sujeitos (profissionais de saúde e usuários) mediadas por tecnologias (materiais e não materiais) utilizadas no processo de trabalho em saúde, cujo propósito é intervir sobre problemas (danos e riscos) e necessidades sociais de saúde historicamente definidas. (PAIM, 1993, apud TEIXEIRA; SOLLA, 2006, p. 24). 
Já o modelo sistêmico propõe três dimensões: uma gerencial, uma organizativa e outra tecnoassistencial ou operativa. A gerencial diz respeito à forma como serão reorganizadas as ações e serviços. A organizativa refere-se às relações entre os equipamentos prestadores de serviços, sugerindo uma hierarquização da produção do cuidado. Já a tecnoassistencial ou operativa refere-se às relaçōes entre "[...] o(s) sujeito(s) das práticas e seus objetos de trabalho" relações essas mediadas pelo saber e pela tecnologia (TEIXEIRA; SOLLA, 2006, p.25).

No final do século XVIII, iniciou-se uma crítica ao ensino da medicina como era até então, baseado no empirismo, tendo a doença como categoria abstrata, acontecendo dentro da faculdade. Os médicos tinham grande liberdade no exercício da medicina, fato que também passa a ser questionado na Europa de então (FOUCAULT, 1994). Com isso buscou-se uma nova forma de organizar o ensino da medicina, voltando-se o olhar à prática clínica e ao hospital. Isso ocorreu devido à confluência de vários fatores: pressões sociais, institucionais, técnicos, a necessidade de se formar médicos para o exército e de se acabar com os "charlatães" (FOUCAULT, 1994, p.78).

Observamos no século XIX uma ruptura do saber médico, passando o hospital de local de assistência aos pobres a lócus privilegiado de atuação da medicina. A clínica foi o modo de se atingir a doença no corpo do indivíduo e um novo olhar sobre a relação da medicina com o espaço social. Vemos a ascensão da Medicina Social na Europa e nos Estados Unidos. Os defensores da medicina como "ciência social" a faziam de forma bem definida, acreditavam que era dever do Estado cuidar e proteger a saúde de seus cidadãos (ROSEN, 1979).

$\mathrm{Na}$ Alemanha parte de uma política médica, como medicina de Estado, tinha o intuito de manutenção da força de trabalho. Na França ela vem atrelada ao ideário da Revolução Francesa (1789), pregando a liberdade de prática da medicina e a democracia. Nos Estados unidos, apresenta um conflito entre a proposta de uma assistência médica fornecida pelo Estado e a medicina privada (ROSEN, 1979).

No Brasil temos, na época do Império, a formulação das primeiras ações governamentais para a área da saúde, ainda restritas às cidades e a algumas doenças epidêmicas que eram sentidas pela economia. Nesse sentido, instituíramse a vacinação, a inspeção dos portos e a polícia sanitária. O início da República veio com o aumento da economia agroexportadora e reformas nos cuidados com a saúde. O governo federal passou a ser responsável pela vigilância sanitária dos 
portos e pelos serviços de saúde da capital, e os estados e municípios ficaram responsáveis pelos cuidados com sua população.

Isso com maior força nas cidades maiores; o interior do país continuava sem muitos cuidados, visto que a prioridade era cuidar das cidades com maior população e, consequentemente, maior impacto na economia. A prioridade era evitar ou debelar as epidemias que acometiam tais cidades, e para isso investiu-se na reforma e limpeza das áreas urbanas.

O SUS vem ancorado em ampla mobilização e luta pelo reconhecimento do direito social à saúde, propondo três níveis de atenção à saúde: primário - a porta de entrada do usuário no sistema, responsável por atuar com açōes voltadas à prevenção e promoção da saúde; secundário - responsável pelo atendimento ambulatorial, reabilitação e o terciário - curativo (FEUERWERKER, 2005).

\section{Atenção básica}

Em 1978 aconteceu um dos eventos marcantes da APS, com a realização da Conferência Internacional Sobre Cuidados Primários de Saúde, em Alma Ata, capital da antiga República Soviética do Cazaquistão. O relatório final da conferência expressava que a saúde é direito humano fundamental e que para ser atingido é necessária a união de vários setores da sociedade e não só da saúde; que a desigualdade no estado de saúde dos povos é algo que existe e é inaceitável; que a proteção e promoção à saúde são fundamentais para o desenvolvimento econômico e social de uma nação; que a participação social nos cuidados em saúde - individual e coletiva - é um direito e um dever; que os governos têm responsabilidades em relação à saúde de seu povo; e chamava atenção aos Cuidados Primários em Saúde.

A declaração também enumerava aquelas que seriam as características dos Cuidados Primários:

- refletem as condições econômicas, políticas e socioculturais dos países;

- atuam sobre os principais problemas de saúde das comunidades de acordo com suas necessidades;

- atuam em conjunto com: educação, nutrição, saneamento básico, planejamento familiar, imunizações, controle de doenças endêmicas, fornecimento de medicamentos, entre outros;

- necessidade de união com outros setores que não só a saúde - intersetorialidade; 
- preveem a participação comunitária no planejamento, organização e controle dos cuidados primários;

- requerem apoio de sistemas integrados;

- trabalho da equipe de saúde e da comunidade.

Esse período marca a crescente discussão acerca da APS, colocando-a como estratégia de organização dos cuidados em saúde, responsável por responder às necessidades de saúde da população por meio de ações localizadas nos territórios, com participação ativa dos indivíduos, tanto individual como coletivamente. Para que isso seja possível, é necessário que haja um novo entendimento da saúde, mais ampla, social e historicamente determinada.

Em alguns países, discute-se o caráter seletivo da APS, colocando-a como programa que oferta uma "cesta" de serviços, geralmente de baixa qualidade e voltada aos pobres. Em outros temos essa oferta mais qualificada, organizada para atender às demandas da população - não só a de baixa renda - e coordenadora da rede de cuidados (GIOVANELLA; MENDONÇA, 2008; LAVRAS, 2011).

Starfield (2002) coloca a APS como o primeiro contato do indivíduo com o serviço de saúde e coordenadora do cuidado, atribuindo à mesma quatro elementos estruturais relevantes para se organizar a APS: a) acessibilidade; b) variedade de serviços; c) definição da população eletiva; d) continuidade); além destes, apresenta dois elementos de desempenho do sistema: a)utilização e b) reconhecimento de um problema.

A acessibilidade é a presença de serviço de saúde próximo à população que o utiliza, bem como a capacidade de lidar com demanda espontânea (não agendada), horário de funcionamento flexível, entre outros. A variedade de serviços diz respeito ao que está disponível para a população, inclusive aquilo que ela acredita que poderia ser ofertado pelo serviço. A população eletiva é a capacidade do serviço de conhecer a população para a qual é referência, suas necessidades e demandas. E a continuidade consiste na forma como o cuidado é prestado ao longo da rede (STARFIELD, 2002, p.61).

A utilização faz referência ao uso e à extensão dos serviços ofertados e o reconhecimento de um problema é necessário para auxiliar no diagnóstico dos problemas e das necessidades de saúde da população (STARFIELD, 2002, p.61). 
A atenção ao primeiro contato refere-se ao acesso e uso do serviço de saúde. A longitudinalidade diz respeito à regularidade da assistência prestada à comunidade, ao vínculo do usuário com a unidade e com seus profissionais e vice-versa. A integralidade supõe que os usuários devem receber todo o cuidado de que necessitam e que isso deve ser garantido e proporcionado pela sua unidade de saúde, mesmo que esse serviço seja ofertado em outro ponto da rede.

A coordenação ou integração faz referência à forma como as informações relativas ao histórico de cuidado do paciente são armazenadas e utilizadas, bem como na continuidade do cuidado prestado pelo mesmo profissional no retorno do usuário ao serviço.

Todos esses conceitos devem ser considerados e utilizados na elaboração, planejamento e organização de uma rede de serviços de $\mathrm{AB}$, visando à resolução de grande parte dos problemas de saúde e a coordenação da rede assistencial.

\section{Atenção Básica no Brasil}

No Brasil, a Atenção Básica (AB) vem colocada como a porta de entrada do sistema, o primeiro contato do indivíduo com o serviço de saúde. Optou-se por utilizar o termo "Atenção Básica", mas ainda hoje tem-se questionado e discutido tal opção. Nossa Atenção Básica tem como base a APS, conceito amplamente estudado e utilizado mundo afora.

Quando da instituição do SUS, passou-se a organizar a rede de serviços de saúde em níveis, com a Atenção Básica ficando a cargo das UBS. Esses locais contavam com equipe de profissionais: médicos- clínicos, pediatras, ginecologistas -, enfermeiros, auxiliares de enfermagem, entre outros, para a condução do cuidado à saúde da população de seu território. Atualmente, a inclinação do Ministério da Saúde é em direção à Estratégia Saúde da Família (ESF), que foi introduzida no cenário nacional primeiramente como Programa Saúde da Família (PSF). É entendida como uma forma de reorganização e qualificação da Atenção Básica, instituindo a família como núcleo central do cuidado.

Seu precursor foi o Programa de Agentes Comunitários de Saúde (PACS), implantado em 1991, no qual os agentes comunitários de saúde (ACS) realizam ações na comunidade com a orientação de um enfermeiro. Primeiramente, o PACS foi implantado no Norte e Nordeste, como estratégia de combate a 

devem residir no território em que atuam, uma vez que constituem o elo entre a unidade de saúde e seus profissionais e a comunidade. Atuam junto ao enfermeiro na definição da área da unidade, no cadastramento das famílias e em ações de orientação e prevenção (BRASIL, 1997).

A ESF deve atuar no território, com o cadastramento da população local, conhecer as famílias ali residentes e suas condições de saúde, elaborar planejamento de ações visando aos determinantes de saúde/doença, identificar as situações de risco presentes em seu território, assim como conhecer e articular os equipamentos sociais ali presentes (BRASIL, 2006). A adoção da ESF pelos municípios vem ancorada na proposta diferenciada de financiamento e como forma de ser possível a oferta de um conjunto mínimo de serviços de saúde que possa dar conta dos problemas prevalentes de saúde das populações de baixa renda.

Propõe-se também, além dessa equipe mínima, a associação de outros profissionais, em outras equipes, como por exemplo, a Equipe de Saúde Bucal (ESB) e mais recentemente o Núcleo de Apoio à Saúde da Família (NASF). Ambas têm como escopo aumentar o leque de ações da atenção básica e maior qualificação dos serviços, com a promessa de ampliação do acesso da população aos profissionais e serviços ofertados por tais equipes. Com isso temos a $\mathrm{AB}$ abrangendo uma gama cada vez maior de açôes e técnicas, como diz Botazzo (2008, p.7):

A atenção básica significa alguma coisa situada entre a promoção da saúde e a reabilitação [...]. [...] iria desde prover condições ambientais, nutricionais e educacionais adequados e exames preventivos às pessoas e grupos sociais, até a cura e a reabilitação dos acometidos.

Todo esse aparato é colocado para a sociedade com a missão de acolher a população que procura pelo serviço de saúde, com suas demandas e necessidades e, em conjunto, resolver os problemas encontrados.

\section{Demanda e necessidades em saúde}

A proposta de mudança no modo de se fazer saúde, de se praticar o cuidado em saúde, tem sido discutida no sentido de o serviço de saúde passar a trabalhar com o foco no indivíduo que o procura, em suas necessidades. Como refere Botazzo (2008, p.9): 
Sem dúvida, é melhor não adoecer; porém, se adoecemos, a intervenção precoce ou

ainda que feita numa altura qualquer do processo, tem a possibilidade de evitar a piora do quadro e limitar o dano.

Com isso espera-se do serviço de saúde que este reconheça e resolva, na medida do possível, os problemas de saúde da população. E da $\mathrm{AB}$ esperamos que seja a captadora de boa parte das condiçōes que afetam a saúde das pessoas. Temos no Brasil a proposição da Política Nacional de Atenção Básica (PNAB), a qual enuncia o "acesso universal" e a "atenção às necessidades de saúde" como parte dos fundamentos e diretrizes da $\mathrm{AB}$, como visto a seguir:

Possibilitar o acesso universal e contínuo a serviços de saúde de qualidade e resolutivos, caracterizados como a porta de entrada aberta e preferencial da rede de atenção, acolhendo os usuários e promovendo a vinculação e corresponsabilização pela atenção às suas necessidades de saúde. O estabelecimento de mecanismos que assegurem acessibilidade e acolhimento pressupõe uma lógica de organização e funcionamento do serviço de saúde que parte do princípio de que a unidade de saúde deva receber e ouvir todas as pessoas que procuram os seus serviços, de modo universal e sem diferenciações excludentes. O serviço de saúde deve se organizar para assumir sua função central de acolher, escutar e oferecer uma resposta positiva, capaz de resolver a grande maioria dos problemas de saúde da população e/ou de minorar danos e sofrimentos desta [...] (BRASIL, 2012, p.20-21).

Esse trecho da PNAB traz à tona alguns conceitos que devem ser vistos mais de perto. O "acesso universal" preconizado pela política é aquele planejado, organizado, operacionalizado pelo profissional de saúde, sempre com vistas à resolução do problema que lhe é apresentado. Castiel (1985, p.19), sobre a função do profissional técnico, afirma: "Uma de suas possíveis funções seria participar na determinação das prioridades em políticas sociais", como a definição das necessidades da população, a distribuição de recursos visando a satisfação dessas necessidades.

Sobre o tema, Franco e Merhy (2005, p.184) discorrem:

A busca pelo serviço de saúde se dá, através da percepção que o usuário tem do que é ofertado por esse serviço. E essa percepção nem sempre é objetiva, porque ela se forma a partir também, de um campo simbólico que o usuário utiliza para formar certa ideia do que o serviço tem a lhe oferecer.

Da mesma forma, Cecilio (2009, p.120) coloca: "A demanda éo pedido explícito, a "tradução" de necessidades mais complexas do usuário." É a forma do indivíduo chegar ao serviço e expressar o que procura. Nem sempre esse pedido será feito de forma clara, concisa, completa, pois é carregado de subjetividade, dúvida, desejo. 

de cuidado:

Um pressuposto para a mudança é tornar trabalhadores e usuários sujeitos do processo, isto é, capazes de um certo protagonismo que muda o sentido do trabalho e produção da saúde.

Construindo juntos - trabalhador e usuário - o modo de produzir saúde dentro das instituições e pelo território que os circunda. Isso se dá no cotidiano do serviço, envolvendo a gestão, os demais parceiros ali presentes e nem sempre levando a consensos.

Teixeira (2010, p. 97) aborda esse tema nos seguintes trechos: "Postulamos [...] que a substância do trabalho em saúde [...] seja a conversa”. A conversa dos trabalhadores com a população, dos trabalhadores entre eles, dos que sempre utilizam aquele serviço, daqueles que ali estão pela primeira vez. Essa conversa deve ser valorizada e estimulada, como forma de troca de saberes, práticas e para que os desejos e expectativas dos envolvidos fiquem claros.

Ainda Teixeira (2010, p.104), acerca dos encontros que ocorrem nos serviços de saúde:

Sendo tais encontros momentos pautados pelo espírito do entendimento e da negociação permanente das necessidades a serem satisfeitas, neles se decide a trajetória necessária de cada usuário através do serviço.

A necessidade quem traz consigo é o usuário, para que possa ser olhada, escutada, desconstruída junto ao profissional. E por fim, um projeto possa ser elaborado com o intuito de sanar ou ao menos aliviar o que o aflige. Como as necessidades são individuais, a proposição de protocolos assistenciais por vezes não dá conta das especificidades de cada um. Devemos então criar um modo para utilizarmos as necessidades de saúde como instrumentos para trabalhadores, gestores, de escuta dos problemas das pessoas que os procuram (CECILIO, 2009).

Em relação à assistência à saúde, Franco e Merhy (2005, p.184) afirmam:

Se ela não for capaz de fazer com que o usuário se sinta de fato protegido, isto é, se a ideia de cuidado, traduzida em atos assistenciais, não estiver coincidindo com a dos usuários, pode-se tornar ruidoso os fluxos comunicantes na relação usuário-serviço de saúde e gerar conflitos e tensóes que interditam a relação de cuidado.

Essa assistência à saúde traduzida em ações e serviços deve contemplar a "cesta de necessidades" (CECILIO, 2009) que cada usuário traz consigo durante a vida e que vai sofrendo modificaçôes, algumas sendo satisfeitas, novas sendo criadas. 


\section{Reflexões}

$\mathrm{A} A \mathrm{~A}$ é detentora de muitas possibilidades de atuação, e no Brasil está sempre sendo rediscutida, renovada, reorganizada, pelo menos no que diz respeito às políticas que a orientam. $\mathrm{O}$ acesso universal, a integralidade das açôes, a coordenação da rede assistencial, são todos atributos da AB. Cecilio (2009, p. 122) nos coloca uma reflexão:

Precisamos deslocar nosso foco de atenção da "atenção primária" como lugar privilegiado da integralidade. Aliás, integralidade não se realiza nunca em um serviço: integralidade é objetivo de rede.

A rede assistencial é formada também pela $A B$, sendo transpassada por saberes técnicos, populares, por indefiniçôes, protocolos assistenciais, escolas, centros comunitários, ou seja, tudo o que toca a saúde das pessoas.

$\mathrm{Na}$ atualidade, a ESF como política instituída para a AB no Brasil se apresenta na forma de programas, produzindo certo ordenamento das práticas de saúde. Cria "procedimentos obrigatórios", o que define e ao mesmo tempo limita as ações dos profissionais, fazendo com que as singularidades sejam desconsideradas (FEUERWERKER, 2005). Lavras (2011, p.871) afirma:

Entre tantos desafios hoje presentes no SUS, deve-se considerar a superação da fragmentação da oferta de ações e serviços de saúde como prioridade, para que se possa responder adequadamente às necessidades de saúde dos brasileiros.

Essa fragmentação leva por vezes à falta de continuidade da atenção, fazendo com que o usuário se "perca” pela rede, transite sem saber qual direção tomar e se sua necessidade será atendida (LAVRAS, 2011). Como dito anteriormente, a saúde não obedece a protocolos ou fórmulas; tem múltiplas determinações e direções. Como bem enunciado por Almeida Filho (2011, p. 15):

[...] a saúde é um problema simultaneamente filosófico, científico, tecnológico, político e prático. Diz respeito a uma realidade rica, múltipla e complexa, referenciada por meio de conceitos, apreensível empiricamente, analisável metodologicamente e perceptível por seus efeitos sobre as condições de vida dos sujeitos.

Tarefa difícil essa de dar conta de tamanha complexidade, por isso a rede, interligada, se faz necessária. Espera-se da rede que contenha inúmeros serviços e equipamentos, em contato, para que possam auxiliar trabalhadores e usuários na busca pela satisfação das necessidades.

$\mathrm{A} A \mathrm{AB}$ tem potencial para isso e uma de suas vantagens é essa constante renovação, fazendo com que ela seja campo de novas experiências e práticas. 
Espera-se do profissional de saúde que esse seja propositivo no seu dia a dia no cuidado em saúde, promovendo espaços de escuta qualificada e acolhedora. Como bem traduz Cecílio (2009, p.120):

[...] a integralidade da atenção, no espaço singular de cada serviço de saúde, poderia ser definida como o esforço da equipe de saúde de traduzir e atender, da melhor forma possível, tais necessidades, sempre complexas mas, principalmente, tendo que ser captadas em sua expressão individual.

A AB será assim mais potente no cuidado das populações, como ordenadora da rede de serviços e centrada no usuário e não nos procedimentos, podendo-se garantir a longitudinalidade do cuidado através da rede. $\mathrm{O}$ mesmo autor sugere uma forma outra de conformação da rede, diferente daquela pensada quando da criação do SUS. Ao invés de serviços dispostos no formato de uma pirâmide, com a $\mathrm{AB}$ na base, uma conformação em círculo. Explicita:

[...] a ideia de que o sistema de saúde seria mais adequadamente pensado como um círculo, com múltiplas "portas de entrada" localizadas em vários pontos do sistema e não mais em uma suposta base. (CECILIO, 1997, p.469).

Isso levaria a uma maior maleabilidade do sistema, possibilitando inclusive maior capilaridade no território. As múltiplas entradas poderiam favorecer a aproximaçáo de equipamentos não considerados, a priori, da saúde, como escolas, associações de bairro. Estes, presentes e atuantes no território, em contato com a mesma população usuária do serviço de saúde. Afinal, não só de saúde vivemos e para que a tenhamos mais viva, precisamos de educação, moradia, alimentação, entre tantos outros fatores.

Discute-se acerca dos determinantes sociais do processo saúde doença, das consequências da má alimentação, da falta de saneamento básico, da precariedade do transporte público nas grandes cidades, mas nada disso é incluído como rede no cotidiano dos serviços e profissionais de saúde. Articular todos esses atores tão próximos é tarefa ainda mais complexa. Escutar, acolher as demandas desses equipamentos, a escola solicitando apoio especializado, as associações de bairro discutindo temas da saúde em suas reuniōes, o lixo que se acumula pelo bairro.

Muitos são os fatores que influenciam a saúde, que operam sobre as necessidades de saúde das pessoas, individual e coletivamente. E os modos como o sistema de saúde recebe e trabalha tais necessidades devem ser continuamente discutidos, renovados, para quem sabe, a $\mathrm{AB}$ se aproxime do ideal, como pontua Cecilio (2012, p.283): 
Uma rede de serviços que, funcionando a pleno vapor e do modo como o movimento

sanitário há anos prescreve, esvaziaria os pronto-socorros, reduziria drasticamente a demanda por atendimentos com especialistas e a realização de tantos e tantos procedimentos laboratoriais considerados desnecessários.

\section{Considerações finais}

O modelo de saúde que aposta na Atenção Básica, na construção coletiva das ações, na organização do processo de trabalho deve ter como base as reais necessidades de quem procura o serviço aliado às informações epidemiológicas.

Atenção Básica é a principal coordenadora e ordenadora do cuidado, estando em contato com os equipamentos presentes no território e com maior proximidade da população de sua responsabilidade. Para tanto, o ideal é contarmos com número reduzido de pessoas por equipe de $\mathrm{AB}$, equipes completas, apostando na valorização das tecnologias leves, ao invés das duras (não que essas não sejam importantes, apenas não devem ser as únicas ou as privilegiadas).

Qualificar o cuidado com processos de trabalho centrados nas reais necessidades daqueles que procuram pelo serviço, sem enfatizar a produção baseada por números. Para isso, deve-se apostar na construção conjunta dos modos de produzir saúde dentro das instituições e pelo território que os circunda. Deve contar com a incorporação de novas estratégias de qualificação e ampliação das açôes, como: projeto terapêutico singular, clínica ampliada e apoio matricial. ${ }^{1}$

\section{Referências}

ALMEIDA FILHO, N. O que é saúde. Rio de Janeiro: Fiocruz, 2011. 160p. (Coleção Temas em Saúde).

BOTAZZO, C. Sobre a Atenção Básica. Os cuidados primários de saúde no contexto da Reforma Sanitária Brasileira. In: BOTAZZO, C.; OLIVEIRA, M.A. (Orgs.). Atenção básica no Sistema Único de Saúde: abordagem interdisciplinar para os serviços de saúde bucal. São Paulo: Páginas \& Letras, 2008. p. 1-12.

BRASIL. Constituição 1988. Constituição da República Federativa do Brasil. Brasília: Senado Federal, 1988.

BRASIL. Ministério da Saúde. Portaria no 1886/GM 18 de dezembro de 1997. Aprova as Normas e Diretrizes do Programa de Agentes Comunitários de Saúde e do Programa de Saúde da Família. Brasília, 1997. Disponível em: http://189.28.128.100/dab/docs/ legislacao/portaria1886_18_12_97.pdf. Acesso em 02 nov 2012. 
Ministério da Saúde. Portaria no 648, 28 de março de 2006. Aprova a Política Nacional de Atenção Básica, estabelecendo a revisão de diretrizes e normas para a organização da Atenção Básica para o Programa Saúde da Família (PSF) e o Programa de Agentes Comunitários de Saúde (PACS). Brasília, 2006. Disponível em: http://bvsms.saude.gov.br/ bvs/saudelegis/gm/2006/prt0648_28_03_2006.html. Acesso em 02 nov 2012.

. Ministério da Saúde. Política Nacional de Atenção Básica. Brasília: Ministério da Saúde; 2012.110 p.

CASTIEL, L.D. O técnico e as necessidades em saúde. Cad Saúde Públ., Rio de Janeiro, v.1, n.1, p.18-24, jan-mar 1985 .

CECILIO, L.C.O. As necessidades de saúde como conceito estruturante na luta pela Integralidade e Equidade na atenção em saúde. In: PINHEIRO, R.; MATTOS, R.A. (Orgs.). Os sentidos da integralidade na atenção e no cuidado à saúde. Rio de janeiro: Cepesc, 2009. p.117-130.

Escolhas para inovarmos na produção do cuidado, das práticas e do conhecimento: como não fazermos "mais do mesmo"? Saúde Soc, São Paulo, v.1, n.2, p.280-89, 2012.

ESCOREL, S. História das políticas de saúde no Brasil de 1964 a 1990: do golpe militar à reforma sanitária. In: GIOVANELLA, L. et al. (Orgs.). Políticas e sistema de saúde no Brasil. Rio de Janeiro: FIOCRUZ, 2008. p.385-434.

ESCOREL, S.; TEIXEIRA, L.A. História das políticas de saúde no Brasil de 1822 a 1963: do Império ao desenvolvimentismo populista. In: GIOVANELLA, L. et al. (Orgs.). Políticas e sistema de saúde no Brasil. Rio de Janeiro: Fiocruz, 2008. p.333-84.

FRANCO, T.B.; MERHY, E.E. Produção imaginária da demanda. In: PINHEIRO, R.; MATTOS, R.A. (Orgs.). Construção social da demanda: Direito à saúde, trabalho em equipe, participação e espaços públicos. Rio de Janeiro: Cepesc, 2005. p.183-95.

FOUCAULT, M. O nascimento da clínica. Rio de janeiro: Forense Universitária, 1994.

GIOVANELLA, L.; MENDONÇA, M.H.M. Atenção primária à saúde. In: GIOVANELlA, L. et al. (Orgs.). Políticas e sistema de saúde no Brasil. Rio de Janeiro: FIOCRUZ, 2008. p.577-625.

LAVRAS, C. Atenção Primária à Saúde e a Organização de Redes Regionais de Atenção à Saúde no Brasil. Saúde Soc, v.20, n.4, p.867-74, 2011.

MATSUMOTO, N.F. A operacionalização do PAS em uma unidade básica de saúde do município de São Paulo, analisada sob o ponto de vista das necessidades de saúde. 1999. Dissertação (Mestrado em Enfermagem) - Escola de Enfermagem, Universidade de São Paulo, São Paulo, 1999. 
NERY, A.A. Necessidades de Saúde na Estratégia Saúde da Família, no município de Jequié - BA: em busca de uma tradução. 2006. Tese (Doutorado) - Escola de Enfermagem de Ribeirão Preto, Universidade de São Paulo, Ribeirão Preto, 2006.

PAIM, J.S. Modelos de atenção à saúde no Brasil. In: GIOVANELLA, L. et al. (Orgs.). Politicas e sistema de saúde no Brasil. Rio de Janeiro: Fiocruz, 2008. p.547-74.

. A reorganização das práticas de saúde em distritos sanitários. In: MENDES, E.V. (Org.). Distrito Sanitário: o processo social de mudança das práticas sanitárias do Sistema Único de Saúde. São Paulo: Hucitec, 1993.

PINHEIRO, R.; CAMARGO JR. K.R. Modelos de atenção à saúde: demanda inventada ou oferta renovada? Algumas consideraçôes sobre modelos de intervenção social em saúde. Physis: Rev.Saúde Coletiva, v. 10, n.1, p.101-119, 2000.

PINHEIRO, R. et al. Demanda em saúde e direito à saúde: liberdade ou necessidade? Algumas considerações sobre os nexos constituintes das práticas de integralidade. In: PINHEIRO, R.; MATTOS, R.A. (Orgs.). Construção social da demanda: direito à saúde, trabalho em equipe, participação e espaços públicos. Rio de Janeiro: Cepesc, 2005. p.13-33. ROSA, W.A.G.; LABATE, R.C. Programa saúde da família: a construção de um novo modelo de assistência. Rev Latino Am Enfermagem, v.13, n.6, p.1027-34, nov-dez 2005.

ROSEN, G. Da polícia médica à medicina social. Rio de Janeiro: Graal, 1979. 401 p.

SANTOS, W.G. Cidadania e justiça: a política social na ordem brasileira. Rio de Janeiro: Campus, 1979.

SCHRAIBER, L.B.; MENDES-GONÇALVES, R.B. Necessidades de saúde e atenção primária. In: SCHRAIBER, L.B., NEMES, M.I.B., MENDES-GONÇALVES, R.B. (Orgs.). Saúde do Adulto: programas e ações na unidade básica. São Paulo: Hucitec, 1996. p. 29-47.

SILVA, J.P.V.; PINHEIRO, R.; MACHADO, F.R. Necessidades, demanda e oferta: algumas contribuições sobre os sentidos, significados e valores na construção da integralidade na reforma do Setor Saúde. Saúde em debate, v.7, n.65, p.234-42, set-dez 2003.

STARFIELD, B. Atenção Primária: equilíbrio entre necessidades de saúde, serviços e tecnologia. Brasília: Ministério da Saúde, 2002. 726 p.

STOTZ, E.N. Necessidades de saúde: mediações de um conceito: contribuições das Ciências Sociais para fundamentação teórico-metodológica de conceitos operacionais da área de planejamento em saúde. Tese (Doutorado em Saúde Pública) - Escola Nacional de Saúde Pública, Fundação Oswaldo Cruz, Rio de Janeiro, 1991. 

das necessidades. In: BRASIL. Ministério da Saúde. Secretaria de Gestão do Trabalho e da Educação na Saúde. VER-SUS Brasil: caderno de textos. Brasília: Ministério da Saúde, 2004. p. 286-301.

TEIXEIRA, R.R. O acolhimento num serviço de saúde entendido como uma rede de conversações. In: PINHEIRO, R.; MATTOS, R.A. (Orgs.). Construção da integralidade: cotidiano, saberes e práticas em saúde. Rio de Janeiro: Cepesc, 2010. p. 91-113.

TEIXEIRA, C.F.; SOLLA, J.P. (Orgs.). Modelo de atenção à saúde. Promoção, vigilância e saúde da família. Salvador: EDUFBA, 2006. 237 p.

\section{Nota}

${ }^{1}$ Ambos os autores participaram igualmente de todas as etapas de elaboração do artigo. 


\section{Abstract}

Social construction of health demand

Health care in Brazil is set as a unified system, running under a legal basis and protected by the Constitution. Health is positioned as a right of every citizen, and both models are defined with a view to the operation of services organized for this purpose. The first level in Brazil is called Basic Care, and its conceptual basis comes from the Primary Health Care (PHC). This paper aimed to understand and analyze how organized is the theoretical production of Public Health in Brazil about the social construction of health demand care in PHC, in order to create a reference to analyze it. The survey was conducted using the terms related to the initial problem: health care demand, basic health care and technical health care models.

Key words: Primary Health Care; health care; health demand; health needs. 